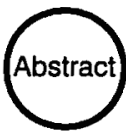

Because noncompliance has efficiency and equity implications, it should be a concern in the design of the commodity tax structure. This article derives the optimal commodity tax conditions and modifications to their standard interpretation when consumers engage in costly border crossing to evade local taxes. It presents a model of costly noncompliance behavior and a modified version of Roy's theorem describing the effect on indirect utility of a tax change when cross-border shopping occurs. This modified Roy's theorem permits the inverse elasticity rule, proportionate shrinkage rule, and covariance interpretation of the optimal tax conditions to be adapted to the case of costly noncompliance.

\title{
OPTIMAL COMMODITY TAXATION WITH COSTLY NONCOMPLIANCE
}

\author{
MARY E. LOVELY \\ Syracuse University
}

Because noncompliance has efficiency and equity implications, it should be a concern in the design of the commodity tax structure. Despite an extensive literature on optimal commodity taxation, however, no revision has been made of standard interpretations of the optimal tax structure accounting for the possibility that consumers engage in costly noncompliance. ${ }^{1}$ As noted by Mirrlees (1986), an "aspect of public policy omitted from the basic models is the evasion and enforcement of government policies" (p. 1199). This article derives the optimal commodity tax conditions and modifications to their standard interpretation when consumers engage in costly border crossing to evade local commodity taxes.

The possibility of commodity tax evasion arises primarily from the heterogeneity of local commodity tax rates, which enable households to reduce their tax burden by crossing the border into a lower-taxing jurisdiction. Because most American states that levy a general sales

AUTHOR'S NOTE: The author thanks, without implication, Paul Courant, Roger Gordon, Douglas Holtz-Eakin, Michael Wasylenko, David Wildasin, and John Yinger for helpful comments. 
tax also levy a use tax, which in practice is a sales tax on purchases by residents made in other jurisdictions, this border-crossing behavior is a form of tax evasion. States have a limited ability to enforce the use tax, given restrictions on their power to force businesses to collect it. ${ }^{2}$ Empirical evidence supports the belief that U.S. consumers do engage in border crossing in response to interjurisdiction tax differentials. ${ }^{3}$

Interjurisdictional differentials also exist in the European Community, which in its progress toward a "Europe without frontiers" faces an increase in cross-border shopping. Many of these cross-border purchases are legal, as there is currently no limit on the amount a traveler may import for personal use. ${ }^{4}$ Nonetheless, these purchases are a form of noncompliance (i.e., tax avoidance), and they influence both the equity and the efficiency of member states' commodity taxation. Difference in value-added tax rates within the EC are large enough to encourage cross-border shopping. As of January 1, 1993, standard value-added tax rates range from $15 \%$ in Germany, Spain, and Luxembourg to $25 \%$ in Denmark. Moreover, rates on a variety of goods such as children's clothes, alcohol, and tobacco vary more widely. ${ }^{5}$

Commodity tax compliance is a concern in optimal tax design because it affects the excess burden of taxation as well as the distribution of the tax burden. Noncompliance is an efficiency issue because of its effect on tax rates and because it is costly. First, to the extent that noncompliance reduces commodity tax revenue, governments with a revenue requirement are forced to raise tax rates in response, which may raise the excess burden of taxation. ${ }^{6}$ Second, border crossing uses real resources, which are a waste from society's viewpoint. ${ }^{7}$ Indeed, it is precisely because border crossing is costly that commodity tax differentials can persist when borders are open. These wasted resources constitute another source of deadweight loss. In addition to these efficiency concerns, noncompliance affects the equity of a given tax structure to the extent that it alters the distribution of the tax burden by income group. ${ }^{8}$

The second section of this article describes a model of a regional economy in which local tax rates differ. This section also describes the household's problem and characterizes the household's choices as to the quantity and location of purchases. The third section presents the 
government's problem and develops a modified version of Roy's theorem to describe the conditions for optimal taxation. We turn next to the case of identical consumers and derive an inverse elasticity rule and a proportionate shrinkage rule accounting for costly noncompliance. Finally, through the use of Diamond's (1975) covariance interpretation, we extend the optimal tax characterization to the case of heterogeneous consumers.

\section{A MODEL OF BORDER CROSSING}

Consider a small mixed economy operating within a larger economic unit. Among the class of all possible indirect tax schemes, the government uses only a linear commodity tax. Moreover, consumers and firms always participate on opposite sides of each market in which they transact, and all commodity taxation takes place on this set of transactions. An implication of this assumption is that if intermediate goods in production and resource transactions among consumers exist, they are not taxed.

All agents in the economy behave competitively. Firms choose net output to maximize profits using technologies that do not involve externalities. There are no profits as all firms use technology exhibiting constant returns to scale. All goods are traded and given free trade between jurisdictions, producer prices of traded goods are the same everywhere. The taxing jurisdiction is economically small, implying that changes in commodity tax rates do not affect producer prices of traded goods. ${ }^{9}$ Firms are legally responsible for tax collections and reporting, and firms within the taxing jurisdiction act in complete compliance with the tax law. ${ }^{10}$

The household's choice of net consumption is denoted by the vector $C^{h}$, where net sales of factor services appear as negative elements. In the absence of lump-sum income, purchases of goods by the household must be offset by sales of factor services to firms. There are $J+1$ commodities in the economy with labor, the only factor service, denoted commodity 0 and the remaining $J$ commodities consumer goods. "Labor is not subject to taxation, and it serves as numeraire with $p_{o}=1$. The price vector faced by the household for transactions 
within the taxation jurisdiction is $p+t^{d}$ where $p$ is the vector of producer prices and $t^{d}$ is the corresponding vector of home taxes.

Tax evasion may be the product of consumer or firm decision making. ${ }^{12}$ We focus here on the consumer and build the model on the presumption that a consumer's decision to evade taxes is motivated by economic factors alone. In particular, consumers receive no disutility from behaving illegally by evading the commodity tax. Consumers are depicted here as choosing between purchases within the home jurisdiction and purchases outside the jurisdiction, with their behavior influenced by commodity tax rates (which determine the benefits of evasion) and by the costs of noncompliance (which determine the costs of evasion).

The household is able to make purchases of traded goods outside or inside the jurisdiction. The consumption vector, $C^{h}$, is the sum of the vector of net purchases made in the home jurisdiction, $C^{\text {dh }}$, and the vector of net purchases made in the neighboring (foreign) jurisdiction, $C^{h h} .^{13}$ Because producer prices are the same everywhere, $p$ is the price received by firms for transactions occurring outside the border of the home jurisdiction. Firms in the neighboring jurisdiction do not collect the tax for the home jurisdiction. Rather, they collect taxes at the neighboring rates, given by the vector $t^{f}$. We assume that some elements of $t^{f}$ are strictly less than the corresponding elements in $t^{d}$. Thus the household can evade commodity taxation by making purchases across the border.

Because the home jurisdiction is small, it is assumed that the neighboring jurisdiction does not change its tax rates in response to revenue-neutral tax changes by the home government. Moreover, it is assumed that the home jurisdiction has no significant opportunity for tax exporting and thus is not concerned with the behavior of residents of the neighboring jurisdiction. ${ }^{14}$ These assumptions simplify the analysis by removing the need to model foreign as well as home behavior. Whereas tax competition issues involving the behavior of foreign governments or residents arise in many settings, we do not address such competition here where the taxing jurisdiction is perceived to be economically small by its neighbors.

We assume that the government funds some activity through commodity taxation without a source of lump-sum revenue. The commod- 
ity tax revenue requirement is denoted $G$ and is measured in terms of the numeraire, labor. We assume that border crossing uses resources, also expressed in terms of labor. These resources may be thought of as untaxed transportation costs. Transport costs are assumed to be an increasing, differentiable, and quasi-convex function of the quantity of foreign purchases and are denoted $R^{h}\left(C^{\prime}\right)$. ${ }^{\text {is }}$

The household's problem ${ }^{16}$ with costly evasion is

$$
\begin{array}{ll}
\operatorname{Max} U^{h}\left[I-\sum_{k}^{j}\left(p_{k}\left(C_{k}^{d h}+C_{k}^{f h}\right)+t_{k}^{d} C_{k}^{d h}+t_{k}^{f} C_{k}^{f h}\right)-R^{h}\left(C^{f}\right), C_{1}^{d h}+C_{1}^{f h}, \ldots, C_{J}^{d h}+C_{J}^{f h}\right] \\
\text { subject to } \begin{array}{ll}
C_{k}^{d h} \geq 0 ; \quad & k=1, \ldots, J \\
& C_{k}^{\text {fh }} \geq 0 ; \quad k=1, \ldots, J
\end{array}
\end{array}
$$

where $I$ indicates lump-sum income in terms of labor and where the budget constraint has been used to solve for $C_{o}{ }^{h} .^{17} U(\bullet)$ is a twice differentiable, strictly quasi-concave utility function. Letting $U_{j}^{h}$ be $\partial U^{h} / \partial C_{j}^{h}$, the Kuhn-Tucker conditions for the household's problem $\operatorname{are}^{18}$

$$
\begin{array}{rlrl}
U_{j}^{h}-U_{o}^{h}\left(p_{j}+t_{j}^{d}\right) & \leq 0, & C_{j}^{d h} \geq 0, & C_{j}^{d h}\left(U_{j}^{h}-U_{o}^{h}\left(p_{j}+t_{j}^{d}\right)\right)=0 \\
U_{j}^{h}-U_{o}^{h}\left(p_{j}+t_{j}^{f}+R_{j}^{h}\right) \leq 0, & C_{j}^{f h} \geq 0, & C_{j}^{f h}\left(U_{j}^{h}-U_{o}^{h}\left(p_{j}+t_{j}^{f}+R_{j}^{h}\right)\right)=0
\end{array}
$$

where $R_{j}^{h} \equiv \partial R^{h}\left(C^{\jmath}\right) / \partial C_{j}^{f}$. By setting the wage at unity, $U_{o}{ }^{h}$ is a measure of the marginal utility of income.

By the quasi-concavity of $U$, the quasi-convexity of $R\left(C^{\prime}\right)$ and nonsatiation, the Arrow-Enthoven sufficiency conditions for a maximum are satisfied. Three types of goods can be distinguished. The first type includes those purchased only domestically, for which $t_{j}^{d}-t_{j}^{f} \leq$ $R_{j}^{h}\left(\bar{C}^{h}\right)$ where $\bar{C}^{h}$ is the chosen vector of foreign purchases. The second type of good is purchased in both locations, with $t_{j}^{d}-t_{j}^{f}=R_{j}^{h}\left(\bar{C}^{h}\right)$. The third type of good is purchased only across the border, with $t_{j}^{d}-t_{j}^{f} \geq$ $R_{j}^{h}\left(\bar{C}^{h}\right)$. Because the resource cost of noncompliance affects the consumption bundle, it affects the level of utility achieved by the household as well as the level of expenditure. If we let $\alpha$ be the vector of parameters of the resource function, we can express indirect utility for household $h$ as $V^{h}\left(p, t^{d}, t^{f}, I ; \alpha\right)$ and the expenditure function as $E^{h}$ $\left(p, t^{d}, t^{f}, U ; \alpha\right)$. 


\section{OPTIMAL COMMODITY TAX STRUCTURE}

The government's problem is to choose the vector $t^{d}$ to maximize a Bergson-Samuelson social welfare function, subject to its revenue requirement of $G .{ }^{19}$ Labor sales by households to firms are not taxed, so $t_{o}$ equals zero. There are $J$ taxable commodities and $H$ households. The optimal tax problem with costly noncompliance may be stated as

$$
\begin{aligned}
& \operatorname{Max}_{t^{d}} W\left[V^{1}\left(p, t^{d}, t^{f}, I ; \alpha\right), \ldots, V^{H}\left(p, t^{d}, l^{f}, I ; \alpha\right)\right] \\
& \text { subject to } G \leq \sum \sum \sum_{t_{j}^{d}} C_{j}^{d h} \\
& h j
\end{aligned}
$$

where the summation over $j$ runs from 0 to $J$ and the summation over $h$ runs from 1 to $H$. I assume that a solution exists and that the Lagrangian conditions are necessary. ${ }^{20}$

Assigning a multiplier of $\mu$ to the government budget constraint, the first-order conditions for a maximum with respect to the $k$ th tax rate are ${ }^{21}$

$$
\sum_{h} \frac{\partial W}{\partial V^{h}} \frac{\partial V^{h}}{\partial t_{k}^{d}}+\mu\left\{\sum_{h} C_{k}^{d h}+\sum_{h} \sum_{j} \frac{\partial C_{j}^{d h}}{\partial t_{k}}\right\}=0, k=1,2, \ldots, J .
$$

To simplify these conditions, we note that the change in household $h$ 's indirect utility resulting from a change in $t_{k}$ can be written

$$
\frac{\partial V^{h}}{\partial t_{k}}=\sum_{j} U_{j}^{h}\left\{\frac{\partial C_{j}^{d h}}{\partial t_{k}}+\frac{\partial C_{j}^{h}}{\partial t_{k}}\right\}
$$

where $U_{j}^{h}=\partial U^{h} / \partial C_{j}$. Without tax evasion, this expression involves no distinction of goods based on location of purchase and can be simplified using Roy's theorem. With tax evasion, modification of this method is needed as some portion of consumption escapes taxation and thus an increase in $t_{k}$ by one unit will not cost $C_{k}{ }^{h}$ in terms of the numeraire.

The modified application of Roy's theorem is derived by differentiating the consumer's budget constraint with respect to $t_{k}^{d}$ : 


$$
0=C_{k}^{i h}+\sum_{j}\left\{\left(p_{j}+t_{j}^{d}\right) \frac{\partial C_{j}^{d h}}{\partial t_{k}^{d}}+\left(p_{j}+t_{j}\right) \frac{\partial C_{j}^{f h}}{\partial t_{k}^{d}}+R_{j}^{h} \frac{\partial C_{j}^{f h}}{\partial t_{k}^{d}}\right\} .
$$

Using the first-order conditions for the consumer's problem, given by (1), this expression can be written as ${ }^{22}$

$$
-\lambda^{h} C_{k}^{d h}=\sum_{j} U_{j}^{h}\left\{\frac{\partial C_{j}^{d h}}{\partial t_{k}}+\frac{\partial C_{j}^{h}}{\partial t_{k}}\right\}
$$

Thus the appropriate form of Roy's theorem is

$$
\frac{\partial V^{h}}{\partial t_{k}^{d}}=-\lambda^{h} C_{k}^{d h}
$$

which describes the effect on indirect utility of a change in the home region consumer price when some portion of consumption may not be subject to taxation. Although the consumer may adjust consumption and the location of purchases in response to a marginal tax increase, these adjustments have no first-order effect on utility.

Because the characterizations of the optimal tax structure that follow rely on this application of Roy's theorem, it is useful to consider the role of resource costs as a source of deadweight loss. Samuelson (1986) notes that taxes that can be fully evaded should be avoided as the resulting distortions are incurred without compensating revenue. ${ }^{23}$ Yet expression (6), which measures the effect on consumer's welfare of a tax increase, does not explicitly include the marginal effect of the tax on resource costs (waste). The reason for this exclusion, of course, is attributable to the consumer's optimization. Adjustments to purchasing locations in response to the tax have only a second-order effect on welfare. These resource costs, however, have influenced the value of both $\lambda$ and $C_{k}{ }^{d}$. Moreover, whereas resource costs do not explicitly figure into marginal loss expressions, they do appear in total deadweight loss calculations. ${ }^{24}$

Letting $\beta^{h}=\left(\partial W / \partial V^{h}\right) \lambda^{h}$, the social marginal utility of income for household $h$, the optimal tax structure meets the conditions

$$
\sum_{h} \beta^{h} C_{k}^{d h}=\mu\left\{\sum_{h} C_{k}^{d h}+\sum_{h} \sum_{j} t_{j} \frac{\partial C_{j}^{d h}}{\partial t_{k}}\right\} k=1,2, \ldots, J .
$$


These conditions differ from the standard case in that they involve domestically purchased quantities and the responsiveness of domestic quantities to tax changes. We emphasize, however, that these quantities and responsiveness measures depend on foreign as well as home fiscal characteristics. For example, if, for some good $m, t_{m}{ }^{d}<t_{m}^{f}$, no foreign purchases of $m$ will be made even if $t_{m}{ }^{d}$ is slightly raised. However, a higher $t_{m}{ }^{d}$ can affect all domestic demands through the usual adjustment of consumption and also through the effect of these adjustments on resource costs, $R\left(C^{f}\right)$. To gain further insight into the optimal tax structure with noncompliance, we turn now to consideration of the standard optimal tax interpretations.

\section{A RAMSEY RULE WITH COSTLY NONCOMPLIANCE}

To simplify the specifications used previously, we assume that all households are identical and have identical costs of noncompliance and that the objective of the government is to maximize the utility of a representative household. In this case, the conditions for an optimal tax structure are

$$
\lambda C_{k}^{d}=\mu\left\{C_{k}^{d}+\sum_{j} t_{j} \frac{\partial C_{j}^{d}}{\partial t_{k}}\right\} k=1,2, \ldots, J .
$$

From these conditions, we obtain a modified "Ramsey rule" if an additional assumption is made. ${ }^{25}$ This assumption, the analog to the standard case, is that there are no cross-price effects except in connection with the numeraire, or $\partial C_{j}^{d} / \partial t_{k}=0$ if $j \neq k$. Besides the well-known restrictions this assumption places on preferences, with noncompliance this assumption also restricts the nature of the resource function. In particular, it implies that consumption adjustments involving good $k$ and the numeraire do not influence $C_{j}^{d}$ through their effect on $R_{j}$. There will be no such influences if $R_{j}$ depends only on $C_{j}$ and not on the full bundle of foreign purchases, $C^{f}$. This assumption about the resource cost function is obviously quite restrictive, as are the conditions necessary to derive an inverse elasticity rule in the standard case.

With these cross-price restrictions, the optimal tax structure becomes 


$$
\frac{\mu-\lambda}{\mu} \frac{1}{\xi_{k k}^{d}}=\frac{t_{k}^{d}}{q_{k}^{d}}, k=1,2, \ldots, J
$$

where

$$
\xi_{k k}^{d} \equiv-\frac{\partial C_{k}^{d}}{\partial t_{k}} \frac{q_{k}^{d}}{C_{k}^{d}}
$$

The distinction from the standard inverse elasticity rule is clear: Tax rates are lower for those goods with large elasticities for domestic demands, ceteris paribus, where the nature of noncompliance costs influences these elasticities. Beyond the usual cases, such goods may be those with slowly rising costs for noncompliance-that is, those goods that are "cheap" at the margin to purchase across the border.

\section{A PROPORTIONATE SHRINKAGE RULE}

In the absence of noncompliance, it has been shown that the optimal tax structure involves an equal proportionate movement along the compensated demand curve for all goods. ${ }^{26}$ The proportionate shrinkage rule is more appealing on theoretical grounds than is the Ramsey rule as it requires no special restrictions on the preferences of the representative household. With evasion, however, this shrinkage interpretation is complicated, as is the Ramsey rule, by the ability of consumers to escape taxation on a share of their consumption. A proportionate shrinkage rule with costly noncompliance can be derived, however, by exploiting the logic underlying the modified version of Roy's theorem presented previously. In deriving the rule, we need not place special restrictions on preferences or on the resource cost function, which were necessary for the modified Ramsey rule.

With identical households, the optimal tax conditions are given by (8). Let $\widetilde{C}_{j}^{d}$ be the compensated demand for good $j$. The Envelope theorem can be used to show that

$$
\frac{\partial E\left(p, t^{d}, t^{f}, U ; \alpha\right)}{\partial t_{j}^{d}}=\tilde{C}_{j}^{d}\left(p, t^{d}, t^{f}, U ; \alpha\right)
$$


where we have assumed that the expenditure function is continuously differentiable. The Slutsky relationship is then

$$
\frac{\partial C_{j}^{d}}{\partial t_{k}^{d}}=\frac{\partial \tilde{C}_{j}^{d}}{\partial t_{k}^{d}}-\frac{\partial C_{j}^{d}}{\partial l} C_{k}^{d}
$$

Using this relationship, the optimal tax conditions can be written as

$$
\lambda C_{k}^{d}=\mu\left\{C_{k}^{d}+\sum_{j} t_{j}\left[\frac{\partial \tilde{C}_{j}^{d}}{\partial t_{k}^{d}}-\frac{\partial C_{j}^{d}}{\partial I} C_{k}^{d}\right]\right\} k=1,2, \ldots, J .
$$

Rearranging, we obtain

$$
\left[\frac{\lambda-\mu+\mu \sum_{j} t_{j} \frac{\partial C_{j}^{d}}{\partial I}}{\mu}\right] C_{k}^{d}=\sum_{j} t_{j} \frac{\partial \tilde{C}_{j}^{d}}{\partial t_{k}^{d}} k=1,2, \ldots, J .
$$

Noting that by the properties of the expenditure function and Young's theorem,

$$
\frac{\partial \tilde{C}_{j}^{d}}{\partial t_{k}^{d}}=\frac{\partial^{2} E}{\partial t_{j}^{d} \partial t_{k}^{d}}=\frac{\partial^{2} E}{\partial t_{k}^{d} \partial t_{j}^{d}}=\frac{\partial \tilde{C}_{k}^{d}}{\partial t_{j}^{d}}
$$

Introducing $\theta$ as the coefficient of $C_{k}{ }^{d}$ in (11), the optimal tax conditions become

$$
\theta C_{k}^{d}=\sum_{j} S_{S_{k j}^{d}} \quad k=1,2, \ldots, J
$$

where $S_{k j}^{d}$ are the Slutsky terms for domestic demands. These compensated elasticities depend not only on preferences but also on the nature of resource costs.

The modified proportionate shrinkage rule can be interpreted by noting that for small taxes the right side of (12) is the change in the domestic demand for good $k$ that would result if the consumer were compensated to stay on the same indifference curve. Because $\theta$ is independent of $k$, the optimal tax structure involves an equal proportionate shrinkage in the compensated domestic demand for all goods, where this compensated elasticity depends not only on preferences but 
also on the costliness of substituting foreign purchases for domestic purchases.

\section{A COVARIANCE INTERPRETATION}

We can extend the proportionate shrinkage rule to the case of heterogeneous households, albeit with added complexity. This extension is based on Diamond's (1975) covariance interpretation of optimal taxation in which the government also is able to offer a head subsidy of equal value to all households. Diamond uses the first-order conditions for the head subsidy to interpret the optimal tax structure. We now apply this procedure to the case of costly noncompliance.

With the household subsidy, the government's problem becomes

$$
\begin{gathered}
\operatorname{Max}_{t^{d}, I} W\left[V^{l}\left(p, t^{d}, t^{f}, I ; \alpha\right), \ldots, V^{H}\left(p, t^{d}, t^{f}, I ; \alpha\right)\right] \\
\text { subject to } G+H I \leq \sum_{h j} \sum_{t j} C_{j}^{d h} \\
h{ }^{d h}
\end{gathered}
$$

where $I$ is the per-household subsidy and $H$ is the number of households. The form of the first-order conditions with respect to tax rates are unchanged by the presence of the household subsidy. The firstorder condition for the household subsidy is

$$
\sum_{h} \beta^{h}+\mu\left\{\sum_{h} \sum_{j} t_{j} \frac{\partial C_{j}^{h h}}{\partial t^{h}}-H\right\}=0 .
$$

We now define

$$
\gamma^{h}=\beta^{h}+\mu\left\{\sum_{h} \sum_{j} t_{j} \frac{\partial C_{j}^{d h}}{\partial T^{h}}\right\}
$$

as the full social marginal utility of income for household $h$, consisting of the direct increase in social utility, $\beta^{h}$, plus the social marginal utility of increased tax revenue when $I^{h}$ is raised.

Using this definition and the Slutsky relationships, the optimal tax conditions (7) become 


$$
\sum_{h} \gamma^{h} C_{k}^{d h}=\mu\left\{\sum_{h} C_{k}^{d h}+\sum_{h} \sum_{j} t_{j} S_{k j}^{d h}\right\} k=1,2, \ldots, J
$$

The first-order condition for the head subsidy indicates that

$$
\mu=\sum_{h} \gamma^{h} / H \equiv \bar{\gamma},
$$

which allows $\mu$ to be interpreted as the average full social marginal utility of income. Note further that

$$
\sum_{h}\left(\gamma^{h}-\bar{\gamma}\right)=0 ; \quad \bar{C}_{k}^{d} \sum_{h}\left(\gamma^{h}-\bar{\gamma}\right)=0 ; \quad \sum_{h}\left(\gamma^{h}-\bar{\gamma}\right) \bar{C}_{k}^{d}=0,
$$

where $\bar{C}_{k}{ }^{d}$ is the average quantity of good $k$ purchased in the taxing jurisdiction. Using these expressions, the optimal tax conditions become

$$
\frac{\sum_{h} \sum_{j} t_{j} S_{k j}^{d h}}{C_{k}^{d}}=\frac{\sum_{h}\left(\gamma^{h}-\bar{\gamma}\right)\left(C_{k}^{d h}-\bar{C}_{k}^{d}\right)}{\bar{\gamma} C_{k}^{d}} k=1,2, \ldots, J .
$$

This expression indicates that the aggregate percentage change in the compensated demand for domestically purchased good $k$ should be proportional to the covariance between the full social marginal utility of income and consumption of domestic good $k$ purchases. Roughly, it suggests that the shrinkage in demand of domestic purchases should be smaller the more consistently deserving households make relatively large domestic purchases.

This covariance result adds to our understanding of the optimal tax structure to the extent that resource costs and the composition of consumption vary systematically by income. Consider, for example, a good for which the marginal resource costs of noncompliance are large so that a relatively high tax rate is needed to induce cross-border purchases. If the demand for this good is highly income elastic, wealthier households will make larger than average purchases at home and the covariance between "deservingness" and domestic purchases will be negative. The optimal shrinkage of such a good would, there- 
fore, be large. By contrast, if households show little variation by income group for these goods (because of a low income elasticity), there will be a minimal covariance between deservingness and domestic purchases. In such a situation, there should be little shrinkage in domestic purchases.

\section{CONCLUSION}

Optimal tax rules for a small economy in which households engage in costly border crossing can be characterized in terms of the response to home taxes of the domestically purchased component of consumption. The responsiveness to home taxes of resources wasted through noncompliance does not appear directly in the optimal tax conditions, as these adjustments have only a second-order effect on a household's welfare. Noncompliance costs do play an important role in optimal tax design, however, as they influence the uncompensated and compensated elasticities of demand used to characterize the optimal tax structure.

\section{NOTES}

1. The optimal commodity tax structure was first treated systematically by Ramsey (1927), with the classic modern treatment provided by Diamond and Mirrlees (1971). Extensions to the theory have been made to include public goods, externalities, international trade, public utility pricing, and the presence of an optimal direct tax. Sandmo (1976) provides a survey of these extensions.

2. A firm is not required to collect the use tax unless the firm has a certain presence within the state, as defined by the courts. Due and Mikesell (1983) describe the use tax and restrictions on a state's ability to collect it.

3. This evidence is reviewed by Fox (1986) and Walsh and Jones (1988).

4. Prior to January 1,1993, the value of a traveler's imports for personal use was restricted to $\$ 660$. See "Country-Hopping Shopping" (1992, 78-9).

5. See "Country-Hopping Shopping" (1992, 78-9).

6. Although it is tempting to conclude that evasion must reduce government revenue, it need not. Consider the case of a jurisdiction that taxes shoes only, with a low tax rate (compared to the neighboring jurisdiction) on right shoes and a prohibitive tax rate on left shoes. The ability to evade taxes on left shoes may increase purchases of right and left shoes, thereby raising domestic government revenue. 


\section{PUBLIC FINANCE QUARTERLY}

7. Yitzhaki (1987) considers a third source of excess burden, that arising from the uncertainty produced by government efforts to enforce tax laws. Additional welfare considerations arise when additional distortions are present. For example, Trandel (1992) considers a model of spatial competition in which evasion can reduce the welfare loss created by a seller's market power.

8. Scotchmer (1992) shows that, in the case of income tax evasion, noncompliance and enforcement bias the tax structure toward regressivity.

9. Nontraded goods can be easily incorporated into the present framework if they are produced using a linear production technology, which ensures that these producer prices also do not change in response to commodity tax changes.

10. Due and Mikesell (1983) suggest that tax collected but not reported is not more than 3\% of the tax due in U.S. states with minimal audit procedures and not more than $0.5 \%$ in states with good audit programs.

11. I choose to assume that households supply one factor, which is untaxed, because most factor transactions are not subject to commodity tax laws. Moreover, I assume that household location is fixed; households do not respond to changes in commodity tax rates by moving to another jurisdiction.

12. Papers by Allingham and Sandmo (1972) and Srinivasan (1973) prompted a substantial literature on tax evasion, much of it concerning income tax evasion. Marelli (1984) and Virmani (1989) consider indirect tax evasion by furms and its implications for production inefficiency.

13. Units purchased in the neighboring jurisdiction but for which the indirect tax is paid voluntarily may be considered part of $C^{d}$. If nontraded goods exist, the elements of $C^{f}$ corresponding to nontraded goods are zeros.

14. In a model in which evasion uses resources, Mintz and Tulkens (1986) characterize the outcome of commodity tax competition between two large, autonomous, neighboring states. They analyze optimal policy using an origin-based commodity tax levied on one of two private goods to finance a local public good.

15. The quasi-convexity of $R\left(C^{\prime}\right)$ reflects economies to "mixed bundles" for transport purposes.

16. For the two-good case, the consumer's problem is similar to that in Mintz and Tulkens (1986), who explore in detail the characteristics of three types of equilibria when regions are not small.

17. An additional constraint, assumed to hold at the optimal choice of $C^{d}$ and $C_{\text {, }}$, is that the quantity of labor sold, $C_{o}$, does not exceed the total time endowment. Nonsatiation is also assumed.

18. The Kuhn-Tucker conditions are necessary because the constraint qualification is met by the assumed properties of $R(\bullet)$.

19. We assume that the government does not engage in cross-border inspections or in punishment of border crossers. In fact, such inspection is very rarely performed by U.S. states and is often precluded between nations by trade agreements. If we were to consider enforcement in the present model, it would be optimal to set the fine for border crossing at the highest level possible and to reduce enforcement to its lowest level, as enforcement is costly to the government but fines are not. When there is the possibility of falsely accusing the innocent, the optimal fine may not be the maximum fine, as argued by Pestieau, Possen, and Slutsky (1992) for the case of income tax evasion.

20. The possibility for multiple solutions to the first-order conditions is well documented. See Atkinson and Stiglitz (1980) and the references cited therein.

21. The multiplier is defined as the marginal social value of tax revenue and thus will be positive for an optimizing government. 
22. This result relies on the assumption that a marginal tax change will alter the purchasing location of only those who are indifferent as to the location of their next purchase. For those who purchase good $k$ only in the neighboring jurisdiction and who are not indifferent as to the location of the next purchase, $U_{j}<\lambda\left(p_{j}+t_{j}{ }^{d}\right)$, and we assume $\partial C_{j}^{d} / \partial t_{k}=0$. For those who purchase good $k$ only in the home jurisdiction and who are not indifferent as to the location of the next purchase, $U_{j}<\lambda\left(p_{j}+t_{j}^{f}+R_{j}\right)$, and we assume $\partial C_{j}^{f} / \partial t_{k}=0$.

23. Samuelson (1986) does not formally address evasion, however, nor does he discuss the possibility that evasion is incomplete.

24. Lovely (1994) includes an expression for the welfare loss from costly commodity tax noncompliance with a given (perhaps optimal) tax structure.

25. See Atkinson and Stiglitz (1980) for a statement of the Ramsey tax problem.

26. Diamond and Mirrlees (1971) attribute the proportionate shrinkage rule to a memorandum for the U.S. Treasury in 1951 published as Samuelson (1986). Mirrlees (1975) notes that the interpretation is an approximation when tax rates are arbitrarily large and derives an analogous condition for an economy with two classes of consumers.

\section{REFERENCES}

Allingham, M., and A. Sandmo. 1972. Income tax evasion: A theoretical analysis. Journal of Public Economics 1:323-38.

Atkinson, A. B., and J. E. Stiglitz. 1980. Lectures on public economics. London: McGraw-Hill. Country-hopping shopping. 1992. The Economist, 26 December, 78-9.

Diamond, P. A. 1975. A many person Ramsey tax rule. Journal of Public Economics 4:335-42.

Diamond, P. A., and J. A. Mirrlees. 1971. Optimal taxation and public product. II: Tax rules. American Economic Review 61:261-78.

Due, J. F., and J. L. Mikesell. 1983. Sales taxation: State and local structure and administration. Baltimore, MD: Johns Hopkins University Press.

Fox, W. F. 1986. Tax structure and the location of economic activity along state borders. National Tax Journal 39:387-401.

Lovely, M. E. 1994. Crossing the border: Does commodity tax evasion reduce welfare and can enforcement improve it? Canadian Journal of Economics 27:157-74.

Marelli, M. 1984. On indirect tax evasion. Journal of Public Economics 25:181-96.

Mintz, J., and H. Tulkens. 1986. Commodity tax competition between member states of a federation: Equilibrium and efficiency. Journal of Public Economics 29:133-72.

Mirrlees, J. A. 1975. Optimal commodity taxation in a two-class economy. Journal of Public Economics 4:27-33.

1986. The theory of optimal taxation. In Handbook of mathematical economics. Vol. 3, edited by K. J. Arrow and M. D. Intriligator, 1197-249. Amsterdam: Elsevier Science.

Pestieau, P., U. M. Possen, and S. M. Slutsky. 1992. The penalty for tax evasion when there are audit errors and taxes are set optimally. Unpublished manuscript, Liege University.

Ramsey, F. P. 1927. A contribution to the theory of taxation. Economic Journal 37:47-61.

Samuelson, P. A. 1986. Theory of optimal taxation. Joumal of Public Economics 30:137-43.

Sandmo, A. 1976. Optimal taxation: An introduction to the literature. Journal of Public Economics 6:37-54. 


\section{0}

\section{PUBLIC FINANCE QUARTERLY}

Scotchmer, S. 1992. The regressive bias in tax enforcement. Public Finance/Finances Publiques 47 (Suppl.): 366-71.

Srinivasan, T. N. 1973. Tax evasion: A model. Journal of Public Economics 2:339-46.

Trandel, G. A. 1992. Evading the use tax on cross-border sales: Pricing and welfare effects. Journal of Public Economics 49:313-31.

Virmani, A. 1989. Indirect tax evasion and production efficiency. Journal of Public Economics 39:223-37.

Walsh, M. J., and J. D. Jones. 1988. More evidence on the "border tax" effect: The case of West Virginia, 1979-84. National Tax Journal 41:261-5.

Yitzhaki, S. 1987. On the excess burden of tax evasion. Public Finance Quarterly 15:123-37.

Mary E. Lovely is an assistant professor of economics in the Maxwell School of Citizenship and Public Affairs at Syracuse University. Her recent work in public economics appears in the Canadian Journal of Economics and in the National Tax Joumal. She also conducts research in international economics and is chair of the International Public Finance Committee of the National Tax Association. 